\title{
ON THE EXACERBATION IN CHRONIC GLOMERULONEPHRITIS
}

\author{
By DAVID SEEGAL, JOHN D. LYTTLE, EMILY N. LOEB, \\ ELIZABETH L. JOST, AND GRACE DAVIS \\ (From the Research Service, 1 First Division, Welfare Hospital, Department of Hospitals; \\ Presbyterian Hospital, Babies Hospital, and the Departments of Medicine and Pediatrics, \\ College of Physicians and Surgeons, Columbia University, New York City)
}

(Received for publication February 21, 1940)

In order to gain a better understanding of the rôle of infection in chronic glomerulonephritis, a study of the exacerbations in this disease was undertaken. Sixty-eight patients with chronic glomerulonephritis were observed closely for periods of from 1 to 8 years. An analysis was made of the incidence of the exacerbations in this group, the presence and nature of the infection preceding each exacerbation, the latent period between the infection and the signs of increased renal inflammation and, finally, the immediate and subsequent effect of each exacerbation on the renal function. It was hoped that these observations might contribute information concerning factors responsible for the progressive nature of chrọnic Bright's disease.

\section{Definition of exacerbation in chronic glomerulonephritis}

Although there is agreement as to the criteria necessary to establish the diagnosis of acute glomerulonephritis, it is difficult to derive a satisfactory definition for the exacerbation in the chronic phase of this disease. Criteria to describe this state are of necessity arbitrary. For the purpose of this investigation we have been guided by the following objective and relatively simple considerations :

It has been assumed that the development of an exacerbation in chronic glomerulonephritis is indicated by an abrupt and marked increase in the degree of hematuria. A concomitant impairment of renal function adds weight to this interpretation, but its absence does not militate against the diagnosis of exacerbation. Since most patients with chronic glomerulonephritis usually pass moderate to large quantities of albumin in the urine, changes in this abnormality are difficult to interpret. Slight variations in the urinary

\footnotetext{
1 Formerly the Research Division for Chronic Diseases.
}

output of erythrocytes, a common finding in chronic glomerulonephritis, do not necessarily signify the presence of an exacerbation.

The pre-exacerbation period includes observations made at any time prior to the onset of the exacerbation. The beginning of the post-exacerbation period is determined with difficulty. It is believed to be present when clinical and laboratory findings have reached the pre-exacerbation level or have become stabilized.

Several instances of increased generalized edema in the absence of changes in the urinary findings were proved to be related to dietary deficiency and these cases were consequently not included in this study. In one such individual, for example, a prolonged alcoholic bout with inadequate food intake resulted in massive edema. A hypoproteinemia well below the patient's previous serum protein level was present. The administration of an adequate diet resulted in a gain of $1 \mathrm{gram}$ per $100 \mathrm{cc}$. in the serum albumin in 1 week with a coincident loss of edema. This phenomenon was apparently due to lack of dietary protein in a patient with nephritis and was not considered to be a true exacerbation.

\section{Case material}

For the past 8 years a large group of patients with chronic glomerulonephritis has been available for study in the Nephritis-Hypertension clinic of Dr. Dana W. Atchley and Dr. Robert F. Loeb at the Presbyterian Hospital and a similar clinic of Dr. John D. Lyttle at the Babies Hospital. These patients have been closely followed in the clinic and have been hospitalized for appropriate studies. In special instances such patients have been under daily observation at the Research Service of the First Division of the Welfare Hospital. It is believed that the opportunity to investigate nephritis both in children and in adults yields a more complete picture of the natural history of this 
disease than would be the case if the data were limited to findings in either children or adults.

Of a total of 68 patients who have been studied for from 1 to 8 years, 13 have exhibited one or more exacerbations during our period of observation.

\section{Relation of age to exacerbation}

Although adults make up the larger proportion of our series of patients with chronic glomerulonephritis, exacerbations have been detected chiefly in the children's group (Table I). The prepon-

TABLE I

Relation of age to exacerbations in chronic glomerulonephritis

\begin{tabular}{c|c|c|c}
\hline Age groups* & $\begin{array}{c}\text { Total number } \\
\text { of cases of } \\
\text { chronic } \\
\text { glomerulo- } \\
\text { nephritis }\end{array}$ & $\begin{array}{c}\text { Total number } \\
\text { of patients } \\
\text { exhibiting } \\
\text { exacerbations }\end{array}$ & $\begin{array}{c}\text { Total number } \\
\text { of } \\
\text { exacerbations }\end{array}$ \\
\hline 14 or under...... & 12 & 8 & 22 \\
Over 14........ & 57 & 5 & 6 \\
\hline
\end{tabular}

* The age in each instance represents the age at death or the present age of those living.

derance of exacerbations in the younger group does not appear to be related to the frequency of clinic or hospital visits. Likewise, the extent of the study was similar for both groups. Because of the higher rate for exacerbation in the younger group, the incidence of hospital admissions is greater for the children than for the adults.

\section{Incidence of exacerbation}

Table II shows the incidence of the exacerbations in the 13 of our 68 patients with chronic glomerulonephritis where these episodes were observed. Six of the patients had only one exacerbation during the period of study, whereas the remaining 7 developed from 2 to 5 exacerbations each. A greater frequency of exacerbations per patient occurred in the younger age group.

\section{Relation of infection to the exacerbation in chronic glomerulonephritis}

In each of the 28 exacerbations in this group, the patient was subjected to clinical, bacteriological and immunological study in order to determine the presence of prodromal infection. This demonstration rested upon close clinical observation and repeated throat cultures for the determination of the presence of Group A hemolytic strepto- coccus. Serum antistreptolysin tests were carried out with a frequency sufficient to detect occult hemolytic streptococcus infections.

Each of the 28 exacerbations followed infection (Table II). All of the 13 patients undergoing exacerbation of their disease had at least one exacerbation apparently related to a preceding hemolytic streptococcus infection (Table II). In all instances the hemolytic streptococcus infection was limited to the pharynx or adjacent tissues.

\section{Exacerbations in chronic glomerulonephritis fol- lowing upper respiratory infection not proved due to the hemolytic streptococcus}

Five of the 13 patients exhibited 8 exacerbations following upper respiratory infections in which the hemolytic streptococcus could not be proved the causative agent (Table II). More adequate study might have demonstrated the presence of hemolytic streptococcus infection in at least 3 of the 8 infections not proved due to hemolytic streptococcus. Each of these patients on other occasions had an exacerbation apparently induced by hemolytic streptococcus infection.

\section{Latent period between prodromal infection and the onset of exacerbation}

The latent period in each of the 28 instances between the onset of the prodromal infection and the onset of the exacerbation was as follows:

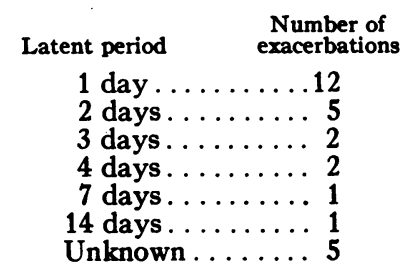

It is seen that, in the main, this latent period is a short one in contrast to that seen in acute glomerulonephritis. The observations confirm those made by others $(1,2)$. It was found that the latent periods for the exacerbations following hemolytic streptococcus infection are approximately the same as those found following upper respiratory infections not proved due to the hemolytic streptococcus.

The rapidity with which upper respiratory infection induces an increase in activity in chronic glomerulonephritis is of interest with regard to 
TABLE II

Exacerbations in 13 patients with chronic glomerulonephritis

\begin{tabular}{|c|c|c|c|c|c|c|c|c|c|c|}
\hline \multirow{3}{*}{ Name } & \multirow{3}{*}{ Age } & \multirow{3}{*}{$\begin{array}{c}\text { Total } \\
\text { months of } \\
\text { observa- } \\
\text { tion }\end{array}$} & \multirow{3}{*}{$\begin{array}{c}\text { Number of } \\
\text { hospital } \\
\text { admissions }\end{array}$} & \multirow{3}{*}{$\begin{array}{l}\text { Number of } \\
\text { out-patient } \\
\text { depart- } \\
\text { ment visits }\end{array}$} & \multirow{3}{*}{\begin{tabular}{l}
\multicolumn{1}{c}{5} \\
\\
Exacerba- \\
tions after \\
hemolytic \\
strepto- \\
coccus in- \\
fections
\end{tabular}} & \multirow{3}{*}{$\begin{array}{c}6 \\
\text { Exacerbations } \\
\text { after upper re- } \\
\text { spiratory infec- } \\
\text { tions not proved } \\
\text { due to hemolytic } \\
\text { streptococcus }\end{array}$} & \multirow{3}{*}{$\begin{array}{c}7 \\
\begin{array}{c}\text { Exacerba- } \\
\text { tions unre- } \\
\text { lated to in- } \\
\text { fection }\end{array}\end{array}$} & 8 & 9 & 10 \\
\hline & & & & & & & & \multicolumn{3}{|c|}{$\begin{array}{l}\text { Effect of exacerbations on renal } \\
\text { function* }\end{array}$} \\
\hline & & & & & & & & $\begin{array}{c}\text { None de- } \\
\text { monstrated }\end{array}$ & $\begin{array}{c}\text { Transient } \\
\text { decrease }\end{array}$ & $\begin{array}{c}\text { Permanent } \\
\text { decrease }\end{array}$ \\
\hline $\mathrm{Ca}$ & 4 & 22 & 5 & 12 & $\begin{array}{l}\text { I } \\
\text { II } \\
\text { III }\end{array}$ & 1 & 0 & $\begin{array}{r}\text { I } \\
\text { II } \\
\text { III } \\
1\end{array}$ & & \\
\hline $\mathrm{Bl}$ & 9 & 37 & 8 & 16 & $\begin{array}{l}\text { I } \\
\text { III }\end{array}$ & $\begin{array}{l}1 \\
2\end{array}$ & 0 & 1 & $\begin{array}{r}\text { I } \\
\text { II } \\
2\end{array}$ & \\
\hline Ro & 12 & 31 & 6 & 13 & II & $\begin{array}{l}1 \dot{\dagger} \\
2 \dagger\end{array}$ & 0 & $\begin{array}{l}1 \\
2 \\
3\end{array}$ & II & \\
\hline Go & 13 & 48 & 5 & 28 & I & & 0 & & I & \\
\hline Al & 13 & 24 & 7 & 22 & II & & 0 & I & II & \\
\hline Gon & .13 & 9 & 3 & 3 & II & & 0 & & II & \\
\hline Wh & 14 & 40 & 5 & 6 & I & & 0 & & I & \\
\hline Le & 14 & 16 & 1 & 9 & I & 1 & 0 & $\begin{array}{l}\text { I } \\
1\end{array}$ & & \\
\hline $\mathrm{Ke}$ & 15 & 23 & 4 & 39 & I & & 0 & & I & \\
\hline Ed & 17 & 6 & 3 & 5 & I & & 0 & & & I \\
\hline $\mathrm{Pa}$ & 17 & 6 & 2 & 4 & I & & 0 & & I & \\
\hline $\mathrm{Du}$ & 18 & 55 & 5 & 20 & I & 1 & 0 & I & $1(?)$ & \\
\hline Mo & 33 & 32 & 2 & 16 & I & & 0 & & I & \\
\hline
\end{tabular}

* The Roman and Arabic numerals correspond to those used in columns 5 and 6. $\dagger$ May have been infection due to hemolytic streptococcus.

the concept that the kidney in this disease is hypersensitive to products of the hemolytic streptococcus. It has been shown (3) that as little as 10 skin test doses of a streptococcus hemolyticus nucleo-protein (4) may produce hematuria in less than 24 hours when injected intravenously into patients with chronic glomerulonephritis.

\section{Effect of the exacerbation on renal function}

In order to evaluate the effect of any single exacerbation on the renal function of the patient with chronic glomerulonephritis, it is at once ap- parent that observations during a prolonged fore period must be at hand as well as repeated studies in the post-exacerbation period. Since patients with chronic glomerulonephritis remain surprisingly well in the absence of gross renal failure, it is difficult to interest some of these individuals in the discipline of clinical investigation unless there is an unusually cooperative attitude on the part of the patient. In the majority of instances it has been possible to obtain satisfactory data, but in some cases the failure of the patient to appear at frequent intervals for study produces 
irreparable gaps in the natural history of the phenomena of exacerbation. For the most part, however, the data obtained appear valid from this point of view.

The status of the renal function was established chiefly by the urea clearance determination, the phenolsulphonphthalein excretion test, the urea ratio value of Mosenthal and Bruger (5), and the serum non-protein nitrogen level. During the periods between exacerbations of the nephritis some of these tests were performed at 1- to 3month intervals. With the occurrence of an exacerbation, selected tests for renal function were usually conducted at weekly intervals. These tests were carried out under the conditions existing in routine hospital and clinic practice. The limitations and the difficulties in interpretation are obvious, but for the purpose of this study the tests are taken to indicate the relative rather than the absolute changes in renal function.

It is seen from Table II that 15 of the 28 exacerbations observed in this series of 13 patients produced a transient drop in renal function. Thirteen of these 15 exacerbations were apparently initiated by a Group A hemolytic streptococcus infection of the pharynx or adjacent tissues. The prodromal upper respiratory infection in the remaining 2 exacerbations was not proved due to the hemolytic streptococcus.

One exacerbation resulted in an apparent permanent decrease in renal function. A reading of the individual case history (Case IX) will indicate the difficulty experienced in evaluating the effect of the exacerbation in patients in the terminal stage of nephritis. It cannot be conclusively stated that the decrease in function, leading to death by uremia in this instance, was dependent upon the exacerbation.

Twelve of the 28 exacerbations failed to produce a demonstrable effect on renal function. These 12 exacerbations occurred in 6 patients, 4 of whom experienced other exacerbations in which a transient decrease of renal function was apparent. One of the remaining patients ( $\mathrm{Ca}$, Case I) showed no decrease in renal function during any of his 4 exacerbations, 3 of which followed Group A hemolytic streptococcus infection. The fourth exacerbation followed an upper respiratory infection not proved due to the hemolytic streptococcus. It is possible that our inability to demonstrate a decrease in renal function following 12 of the exacerbations reported here is related either to the slight degree of the renal flare-up or to our failure to employ appropriate renal function tests at sufficiently frequent intervals.

\section{DISCUSSION}

The 13 patients ${ }^{2}$ who experienced exacerbations of glomerulonephritis have been observed in the following manner: The tests for the activity of the nephritis were the usual ones. In addition to routine urinalyses, frequent Addis counts were performed. Records were made of the blood pressure, eyeground findings, serum protein values, the presence of edema, and the hemoglobin and red blood cell count values to determine the progress of the disease. The tests for renal function and the methods used for the demonstration of the presence or absence of hemolytic streptococcus infection have been described above.

Although there is agreement that hemolytic streptococcus infection is the chief initiating factor in acute glomerulonephritis, doubt prevails concerning the agent responsible for the maintenance and progression of the disease chronic glomerulonephritis. The failure to reproduce chronic glomerulonephritis experimentally in animals with the hemolytic streptococcus limits the investigation of the rôle of infection in this disease to clinical studies. The major work in this field has been carried on by Longcope and his associates $(6,7,8)$. Winkenwerder, McLeod and Baker (2) analyzed the data accumulated by Longcope and concluded that "Persistence of the streptococcus was characteristic of the chronic stage of the disease." These workers report the contributions of others whose opinions are pertinent to the question.

In the past 8 years at the Presbyterian and Babies Hospitals in New York City it has been possible to collect evidence concerning the relation between infection, particularly of the upper respiratory tract, and the course of chronic glomerulonephritis in 68 patients. A report of the degree of parallelism which exists between the presence of infection and the velocity of the nephritis in this group of patients is now being prepared. The present communication is limited to the study of

\footnotetext{
2 See protocols.
} 
the exacerbations in chronic glomerulonephritis. The chief points to be determined were: (1) the frequency with which exacerbation occurs, (2) the infectious factors initiating the exacerbation, and (3) the effect of the latter upon the course of the nephritis.

The data which have been presented indicate that in this series of 68 patients observed from 1 to 8 years, unequivocal exacerbation occurred in only 13 members of the group. Attention has been directed to the difficulty of delimiting the criteria necessary to determine the presence of the exacerbation. A sharp increase in the degree of hematuria occurred in 4 patients who have not been included in this series. The case histories of the individuals, all adults, have been excluded for the following reasons:

Patient Ar. The hematuria which occurred under our observation followed the intravenous injection of a hemolytic streptococcus nucleoprotein.

Patient Pf. The hematuria was always so variable it was impossible to describe any single episode as indicative of an exacerbation.

Patient Fo. The hematuria occurred terminally and the patient was not available for adequate study.

Patient $H u$. This patient was observed early in our study and adequate immunological and renal function tests were not performed.

The addition of these cases to our series would not have altered the conclusions beyond increasing the number of individuals in the adult group.

In our experience frank exacerbation in chronic glomerulonephritis occurs only after infection. As a rule, this infection is caused by Group A hemolytic streptococcus. Winkenwerder, McLeod and Baker (2) studied the etiological factors in 42 exacerbations in " chronic hemorrhagic nephritis." They found that 42 of 126 infections which occurred during the course of the disease in their series appeared to initiate an exacerbation. Fifty-five per cent of these infections were shown to be of hemolytic streptococcus origin. They further observed that 30 per cent of 84 infections unaccompanied by exacerbation were also of hemolytic streptococcus origin. These workers believed that their data indicated " that when infection is followed by exacerbation of nephritis streptococcus is apt to be found."
In our series of 68 patients with chronic glomerulonephritis there were 350 infections of various types, of which 68 were shown to be of hemolytic streptococcus origin. Twenty (71 per cent) of the 28 exacerbations observed in the entire group followed hemolytic streptococcus infection, whereas only 48 hemolytic streptococcus infections occurred among the 322 other infections (15 per cent) which failed to incite an appreciable exacerbation. In this respect, our data confirm those presented by Winkenwerder and his associates. The lower percentage of hemolytic streptococcus disease among infections failing to produce exacerbations in our group may be due to the greater frequency of visits of patients. Because of this the number of mild infections (not of hemolytic streptococcus origin) of the upper respiratory tract which we have observed may be greater than that observed by Winkenwerder, McLeod and Baker. It should be emphasized that all infections occurring during the acute and early subacute stages of glomerulonephritis are excluded from this survey.

As already stated, careful study of our patients during the period of exacerbations shows that each of these episodes was preceded by an infection. Winkenwerder, McLeod and Baker, however, have observed exacerbations of nephritis "despite the failure to demonstrate any inciting factor." This divergence may depend upon the interpretation of the criteria required to define exacerbation. It may also rest in part upon the fact that clinical and bacteriological determination of the presence of hemolytic streptococcus infection may fail in some cases to yield positive data. With the use of the antistreptolysin test, however, the presence of hemolytic streptococcus infection may be detected in the absence of bacteriological data. It is possible that some of the exacerbations in Winkenwerder, McLeod and Baker's series were observed prior to the general use of this test.

Our accumulated evidence demonstrates that a transient decrease in renal function is a frequent result of the exacerbation in chronic glomerulonephritis. Fifteen of the exacerbations effected such a temporary decrease in renal function. In contrast, 12 exacerbations could not be shown to have altered the functional level of the kidneys. The exacerbations in this latter group were in- 
itiated by hemolytic streptococcus infection in 6 instances and the remaining exacerbations followed upper respiratory infections in which the hemolytic streptococcus could not be proved the causative agent. A permanent and apparently progressive decrease in renal function followed an exacerbation in only one patient in our series. In this instance the terminal state of nephritis was at hand when the exacerbation appeared. It is obviously difficult to evaluate significant changes in renal function in patients who are in the terminal stage of chronic glomerulonephritis.

The failure of the majority of exacerbations in this series to produce a permanent decrease in renal function was surprising to us. It was felt that if repeated or continuous hemolytic streptococcus infection was the mechanism which caused progressive renal damage in patients with chronic glomerulonephritis, one would expect that the hemolytic streptococcus infection which induced an exacerbation of nephritis would be particularly effective in permanently reducing renal reserve. The analysis of the 27 exacerbations reported here lends little evidence to this concept unless the suggestion is accepted that a single hemolytic streptococcus infection in a patient with chronic glomerulonephritis can initiate a type of renal damage which perpetuates itself in autocatalytic form for months or years.

It is possible that the return of the functional values to the pre-exacerbation level after the depression induced by the renal flare-up is more apparent than real. Although the post-exacerbation tests for renal function may be normal, nevertheless a reduction of the mass of functioning renal tissue may have occurred. This possibility is shown diagrammatically in Figure $10(A)$.

In this hypothetical instance 3 exacerbations of nephritis have induced 2 periods of "transient" and 1 period of "permanent" decrease in renal function. However, a reduction in the per cent of functioning renal tissue has occurred following the first 2 exacerbations despite our inability to demonstrate this state by the usual function tests. This difficulty is partially met in instances where exacerbation occurs in an individual with chronic glomerulonephritis whose renal function levels are already decreased.

An alternative hypothesis to that shown in Fig- ure $10(A)$ is diagrammatically shown in Figure $10(B)$. This mechanism presumes that the velocity of the nephritis is established at its initiation through an unknown cause. Exacerbations produce dramatic episodes but do not significantly alter the slope of the curve. It is impossible at this time to designate either hypothesis as correct.

Addis (9) in 1931 stated that in his experience none of the infections and incidents which led to temporary increases in the intensity of the renal lesion seemed to have resulted in any irreparable loss of secreting tissue. He further described 2 cases in which repeated exacerbations seemed not to be accompanied by a significant decrease in the "amount of functioning renal tissue." Winkenwerder, McLeod and Baker (2) have shown " that recurring infections, in spite of their relation to exacerbations, do not necessarily determine the ultimate outcome of the disease, for partial recovery to the latent stage or complete recovery from nephritis was not prevented by such infection, and whereas the progressive group was characterized by recurring infections in some cases, in others this factor was not obvious and in a few patients active infection was never demonstrated." Osman (10), who has studied the "late-results" of "acute nephritis," believes that the number of attacks of nephritis (exacerbations?) has apparently no influence on the ultimate prognosis. Leiter (11) has stated that in most patients with chronic nephritis . . " further decrease of function occurs as the result of definite acute exacerbations following acute streptococcal infections, as the result of slow but continued destruction of renal parenchyma in the absence of obvious infection anywhere in the body or because of organic vascular changes in the kidney. ...."

It seems evident, therefore, that the exacerbation in chronic glomerulonephritis is initiated chiefly by hemolytic streptococcus infection and that the exacerbation usually effects only a transient drop in renal function.

Exacerbation as defined here is seen to be chiefly a manifestation of childhood glomerulonephritis. Although the adult group has been subjected to careful study, the incidence of exacerbation as defined here has been low. There is only one patient in this group exhibiting exacerbation over the age of 20 . 


\section{SUM MARY AND CONCLUSIONS}

1. The natural history of each of 28 exacerbations of nephritis occurring in 13 of a series of 68 patients with chronic glomerulonephritis is described. In the main, these individuals were under close observation for periods of from 1 to 8 years.

2. An abrupt, marked increase in hematuria with or without a concomitant impairment of renal function is assumed to indicate the occurrence of an exacerbation in chronic glomerulonephritis.

3. The frequency of exacerbation so defined is greater in the young than in the adult group in this series.

4. All 13 of the patients experienced exacerbations initiated by Group A hemolytic streptococcus infection. Five of these patients underwent additional exacerbations related to upper respiratory infections which could not be proved due to the Group A hemolytic streptococcus.

5. In the total series of 68 patients with chronic glomerulonephritis there were 350 infections of various types, of which 68 were shown to be of hemolytic streptococcus origin. Twenty (71 per cent) of the 28 exacerbations followed hemolytic streptococcus infection, whereas only 48 hemolytic streptococcus infections occurred among the 322 (15 per cent) infections which failed to incite an appreciable exacerbation.

6. No exacerbation of chronic glomerulonephritis in this series occurred without concomitant infection.

7. The latent period between the onset of the infection and the exacerbation was from 1 to 4 days in the majority of instances. This latent period, as pointed out by others, is much shorter than that seen between the infection and the onset of acute glomerulonephritis.

8. A common effect of the exacerbation was to produce a transient decrease in renal function. Ten of the 13 patients exhibited 1 to 4 such exacerbations.

Six patients underwent exacerbations in which no effect on renal function could be demonstrated. Four of these 6 patients, however, experienced other exacerbations in which a transient decrease in renal function occurred. Only 1 patient developed a permanent decrease in renal function following an exacerbation, but the nephritis at this time was in the terminal stage.

9. It may be concluded that the exacerbation in chronic glomerulonephritis is the result of infection and that this infection is due mainly to invasion by the Group A hemolytic streptococcus. The chief effect of the exacerbation is the production of a transient rather than a permanent decrease in renal function. However, since there is no correlation between mass of functioning renal tissue and renal function tests when the latter are within the range of normal, it is impossible to determine whether or not the total mass of renal tissue has been reduced in those cases where renal function tests indicate only a transient decrease in function.

Dr. David P. Earle, Jr., assisted in the collection of the data from several of the patients in this series.

\section{PROTOCOLS}

\section{Case I $(\mathrm{Ca})$}

This 4-year old boy was first seen by us on January 26,1938 , in what appeared to be a typical attack of acute glomerulonephritis. However, since there was an unequivocal record of hematuria associated with fever 6 months earlier, it was believed that the nephritis probably was initiated at that time.

Certain details of the episodes of exacerbation of the nephritis on January 18,1938, March 20, 1938, January 5, 1939, and April 26, 1939, are shown in Figure 1. It is seen here that data are available on the degree of albuminuria, hematuria, edema, blood pressure, nonprotein nitrogen of the serum and the urea ratio prior to, during, and after the respective exacerbations of the nephritis.

It is apparent that the patient experienced 4 exacerbations of nephritis over a 15-month period. In each exacerbation of his disease there was an increase in albuminuria and hematuria above the previous base line, but it is also evident that in each instance these urinary findings returned to the pre-exacerbation level. On the basis of the other evidence at hand with respect to edema, blood pressure, serum nonprotein nitrogen, and urea ratio determinations, it cannot be shown that a significant drop in renal function is associated with any of these exacerbations. A single urea clearance test performed during the third exacerbation showed a value of 97 per cent of normal (not shown on chart).

The findings in this patient with respect to the effect of exacerbation on renal function differ from those seen in the majority of our cases in that no significant depression in renal function is associated with the exacerbations. It is possible, however, that frequent urea clearance determinations and additional renal function tests might have detected such a change. 


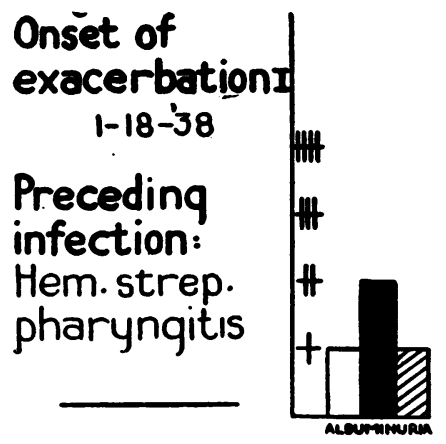

Onset of exacerbation II

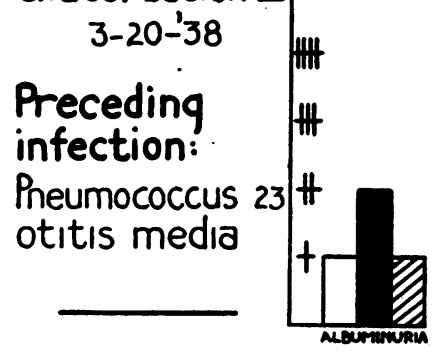

Onset of exacerbation II

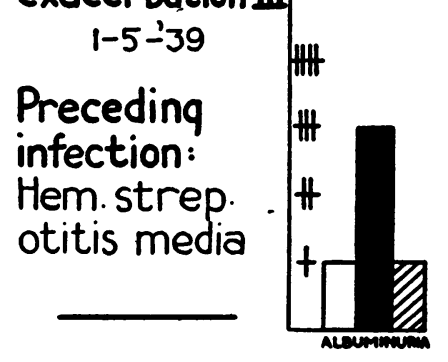

Onset of exacerbation

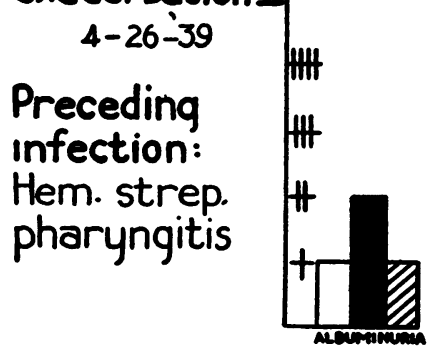

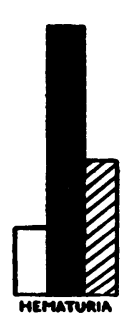
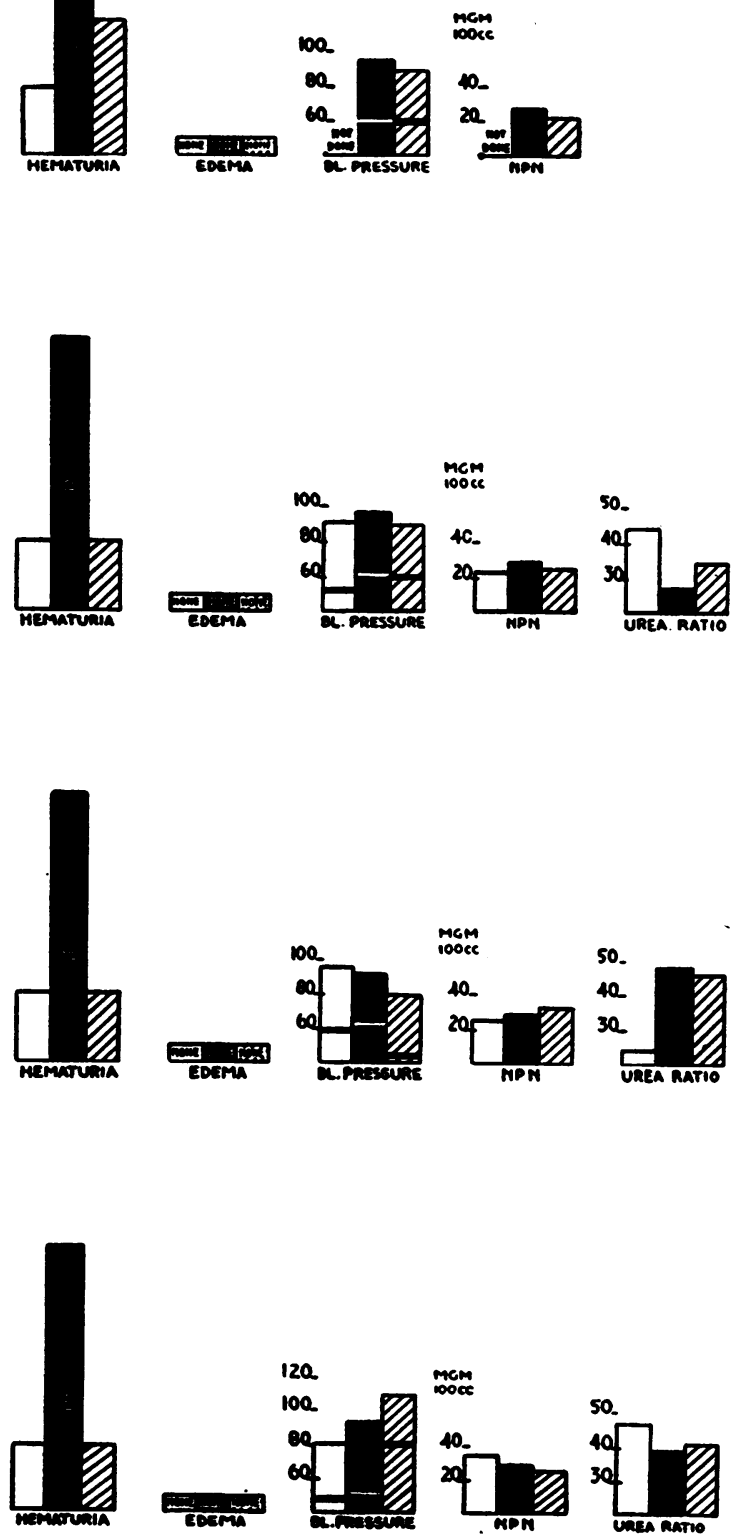

$\square$ Maxımum finding prior to exacerbation Maximum finding during exacerbation Maximum finding after exacerbation

Fig. 1. Case I (Ca). Observations Before, During, and After Four Exacerbations in Course of Chronic Glomerulonephritis 


\section{Case II $(B l)$}

This boy, who is now 9 years old, was said to have had "kidney trouble" following scarlet fever at the age of 4 (1934). In 1935 there was a history suggesting an exacerbation of the nephritis occurring during an episode of mastoiditis for which a mastoidectomy was performed.

He was first seen by us in May, 1936, when an incision and drainage was performed for the relief of inguinal lymphadenitis with abscess. The culture of the pus yielded "hemolytic staphylococcus aureus" but the antistreptolysin level was found to be $\mathbf{2 5 0}$ units. Four months later this value had dropped to 111 units. There was no evidence for an exacerbation of the nephritis associated with this infection.

During the next 37 months of observation in which there were 8 hospital admissions and 16 clinic visits, there were 5 exacerbations, 4 of which were associated with a transient decrease in renal function.

Since all these exacerbations occurred between July, 1938 and April, 1939, it was impossible to determine accurately the fore period for each bout. The natural history of the nephritis and associated infections is herewith described.

Exacerbation I occurred on July 3, 1938, following an $H$. influenzae otitis media. There was no evidence for hemolytic streptococcus infection at this time. The hematuria, which was minimal $( \pm)$ before the flare-up, became ++++ during the exacerbation. $\mathrm{A}++$ albuminuria became ++++ during the renal flare-up and remained at this level permanently. There was no evidence for an associated depression in renal function. The urea clearance of 60 per cent of normal and the urea ratio of 50 remained constant throughout the exacerbation and thereafter. Following this acute episode the hematuria returned to its previous level.

Exacerbation II occurred on August 25, 1938. This was apparently related to a hemolytic streptococcus pharyngitis. S. hemolyticus and $H$. influenzae were cultivated from the pharynx, but evidence for invasion by hemolytic streptococci was shown by the rise of the antistreptolysin titer from 62 to 166 units. Hematuria, edema and the serum nonprotein nitrogen level increased through this bout only to return to the previous approximate base line in the post-exacerbation period. These data are shown below.

\begin{tabular}{|c|c|c|c|}
\hline & $\begin{array}{c}\text { Before } \\
\text { exacerbation }\end{array}$ & $\begin{array}{c}\text { During } \\
\text { exacerbation }\end{array}$ & $\begin{array}{c}\text { After } \\
\text { exacerbation }\end{array}$ \\
\hline $\begin{array}{l}\text { Hematuria } \ldots \ldots \ldots \ldots \\
\text { Edema } \ldots \ldots \ldots \\
\text { Nonprotein nitrogen . }\end{array}$ & $\begin{array}{l}+ \\
\pm \\
25\end{array}$ & $\begin{array}{r}+t+ \\
+t \\
46\end{array}$ & $\begin{array}{l}+ \\
\pm \\
33\end{array}$ \\
\hline
\end{tabular}

Exacerbation III occurred on October 14, 1938. This was apparently related to a mild pharyngitis. Group A hemolytic streptococci were isolated from the throat culture and the antistreptolysin titer rose from a base line of 83 units to a peak of 166 units. The hematuria, which was minimal $( \pm)$ before the exacerbation, became ++++ during the exacerbation and dropped to + with the termination of the bout. Although there were no significant changes in edema, blood pressure, and the serum nonprotein nitrogen values and urea clearance figures during this episode, the base line urea ratio of 40

\section{Explanation of Figures on Chart}

The values for the albuminuria are the conventional ones.

In this and subsequent charts the hematuria, as determined in the sediment of the usual centrifuged specimen, is designated in the following manner:

1-5 red blood cells per H.P.F. ............... +

$6-15$ red blood cells per H.P.F. ............... ++

16-25 red blood cells per H.P.F. .............. +++

Above 25 red blood cells per H.P.F. ............ +++

The presence of gross hematuria is so indicated.

In a number of the patients Addis counts were made to determine the degree of hematuria. This finding is so designated on the graph.

The values for edema are expressed as follows:

Slightest demonstrable edema $\ldots \ldots \ldots \ldots \ldots \ldots \ldots \ldots$ +

Edema of face and ankles ..................... ++

Generalized edema with fluid in visceral cavity ...... ++++

The figure +++ is arbitrarily used to describe the degree of edema between ++ and ++++ .

The values for the systolic blood pressure level are designated by the height of the column. The heavy horizontal bar shows the diastolic peak.

The nonprotein nitrogen levels are expressed as serum values. The figures for the urea ratio, urea clearance and phenolsulphonphthalein excretion tests are self-explanatory. 
rose to 70 and dropped to 55 after the exacerbation. Possibly too much reliance should not be placed on the urea ratio values here since no comparable changes occurred in the urea clearance figures.

Exacerbation IV occurred on March 7, 1939. This episode was preceded by abdominal pain, vomiting, temperature of $102^{\circ}$, and isolation from the blood of a nontypeable pneumococcus. From clinical evidence it was felt that a pneumococcus peritonitis existed, but this point was not proved. Sulfapyridine therapy cured the pneumococcus infection. Antistreptolysin determinations showed values within normal limits. This infection apparently induced a transient decrease in renal function as is shown below.

\begin{tabular}{|c|c|c|c|}
\hline & $\begin{array}{c}\text { Before } \\
\text { exacerbation }\end{array}$ & $\begin{array}{c}\text { During } \\
\text { exacerbation }\end{array}$ & $\begin{array}{c}\text { After } \\
\text { exacerbation }\end{array}$ \\
\hline $\begin{array}{l}\text { Hematuria } \ldots \ldots \ldots \\
\text { Edema } \ldots \ldots \ldots \\
\text { Nonprotein nitrogen } \\
\text { Urea clearance...... } \\
\text { Urea ratio } \ldots \ldots \ldots \ldots\end{array}$ & $\begin{array}{l}+ \\
+ \\
31 \\
40 \% \\
55\end{array}$ & $\begin{array}{c}+t+ \\
++t \\
58 \\
38 \% \\
68\end{array}$ & $\begin{array}{l}+ \\
+ \\
28 \\
60 \% \\
38\end{array}$ \\
\hline
\end{tabular}

Exacerbation $V$, which occurred on April 1, 1939, followed an otitis media with post-auricular abscess. Group A hemolytic streptococci were isolated from the abscess exudate and the antistreptolysin titer rose from a base line of 25 to 33 units to a peak of 715 units. This exacerbation was characterized by the following changes in the renal status:

\begin{tabular}{l|c|c|c}
\hline \hline & $\begin{array}{c}\text { Before } \\
\text { exacerbation }\end{array}$ & $\begin{array}{c}\text { During } \\
\text { exacerbation }\end{array}$ & $\begin{array}{c}\text { After } \\
\text { exacerbation }\end{array}$ \\
\hline Hematuria $\ldots \ldots \ldots \ldots$ & + & ++ & \pm \\
Edema ............. & \pm & \pm & \pm \\
Blood pressure....... & $140 / 90$ & $160 / 100$ & $130 / 90$ \\
Urea clearance...... & $38 \%$ & $38 \%$ & $60 \%$ \\
Nonprotein nitrogen... & 32 & 43 & 27 \\
Urea ratio.......... & & 61 & 38 \\
\hline
\end{tabular}

It is probable that a significant transient decrease in renal function occurred during this exacerbation.

The course of this patient's nephritis during 5 exacerbations of the disease is of interest with respect to the comparative functional level before and after the renal flare-ups. A transient decrease in function was demonstrated during the 3 exacerbations related to hemolytic streptococcus infection and the single exacerbation apparently due to the non-typeable pneumococcus infection. No change in renal function was observed during the exacerbation which apparently followed the $H$. influenzae otitis media. It is further seen that a comparison of the renal competence before and after the 5 exacerbations which occurred between July, 1938 and April, 1939 shows no striking difference. The urea clearance on June 22, 1938, was 63 per cent of normal, on June 2, 1939,60 . The urea ratio on June 22,1938 , was 43 , on June 2, 1939, 38 (normal below 50). The serum nonprotein nitrogen value was $33 \mathrm{mgm}$. per $100 \mathrm{cc}$. on June
22,1938 , and $27 \mathrm{mgm}$. per $100 \mathrm{cc}$. on June 2,1939 . It is evident, therefore, that in this patient frequent exacerbations of glomerulonephritis have resulted in only transient drops in renal function.

\section{Case III (Ro)}

This girl, who is now 12 years old, has one sibling who has had both rheumatic fever and glomerulonephritis. The onset of acute nephritis in our patient probably occurred in July, 1932. From the history it would appear that exacerbations of the nephritis occurred in December, 1932, after a bronchitis; in May, 1936, after a sore throat; and in August, 1936, from an unknown cause.

The patient first came under close observation by us in September, 1936. During the subsequent 3 years she was studied through the course of 5 exacerbations of nephritis. An additional exacerbation occurred outside our observation. This bout is not included in our description. It is seen from Figure 2 that all 5 exacerbations were characterized by a sharp increase in the degree of albuminuria and hematuria. In all instances there was a decrease in this abnormality to the approximate basal level after the renal flare-up.

Exacerbation I occurred on March 12, 1937, when the patient was 10 years of age; it appeared to be related to a preceding infection described as "grippe." The available data cannot exclude the possibility that the hemolytic streptococcus played a rôle in this infection. The evidence at hand suggests that this exacerbation failed to produce a drop in renal function.

Exacerbation II occurred on May 26, 1937, and was preceded by a hemolytic streptococcus pharyngitis. The antistreptolysin titer rose from a base line of 144 units to 715 units. This exacerbation induced a temporary drop in renal function. There was a transient + edema and the serum nonprotein nitrogen level rose from 22 to 59 and then dropped to $28 \mathrm{mgm}$. per $100 \mathrm{cc}$. in the post-exacerbation period.

Exacerbation III occurred on October 28, 1937, and was preceded by lobar pneumonia. Pneumococci could not be isolated from the sputum. During a relapse of the pneumonia 1 month later, in which gross hematuria reappeared, hemolytic streptococci and not pneumococci were isolated from the sputum. Antistreptolysin determinations were not carried out at sufficiently frequent intervals to rule out the possibility that the pneumonia was of hemolytic streptococcus origin. There was no evidence of disturbance in renal function during this flare-up.

Exacerbation IV occurred on May 1, 1938, and was preceded by a hemolytic streptococcus pharyngitis. The throat cultures during this episode showed the predominant organism to be a Group A hemolytic streptococcus. The base line antistreptolysin titer of 333 units remained unchanged following the sore throat. Nevertheless, it was felt that infection by the hemolytic streptococcus had occurred. During this exacerbation (Figure 2) a transient edema, hypertension, slight rise in the serum nonprotein nitrogen value and a sharp rise in the urea ratio developed. The urea clearance during this bout was 
Onset of exacerbation I $3-12-37$

Preceding infection: "Grippe"
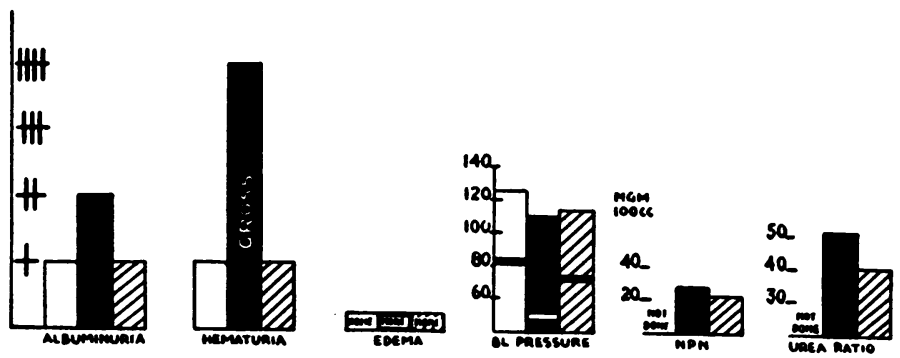

Onset of exacerbation II $5-26-37$

Preceding infection: Hem. strep. pharyngitis
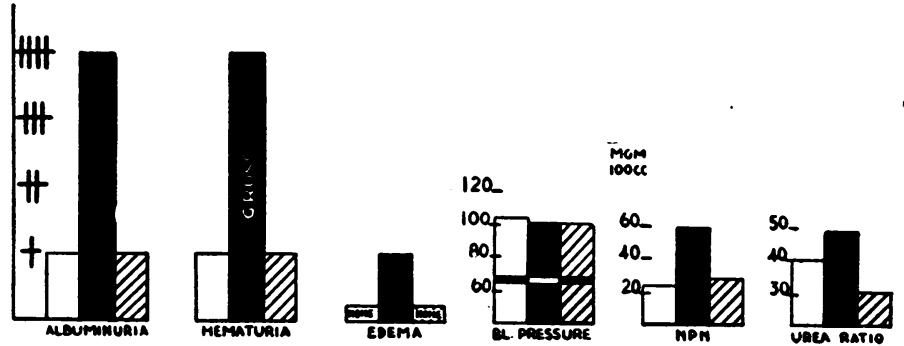

Onset of exacerbation m $m$ $10-28-37$

Preceding infection Lobar pneumonia; causative agent unknown
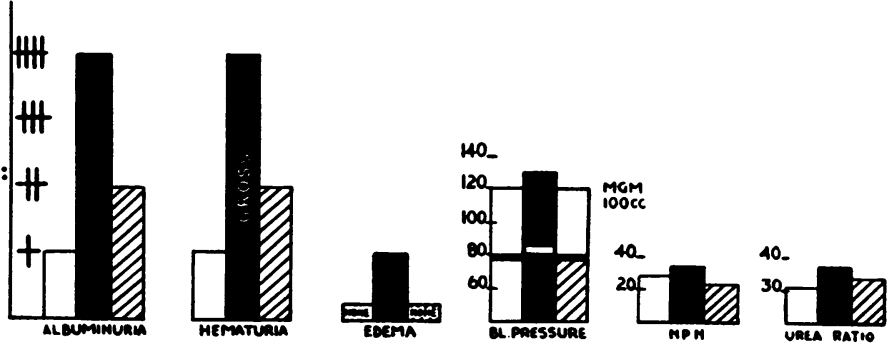

Onset of exacerbation II $5-1-38$

Preceding infection: Hem strep. pharyngitis
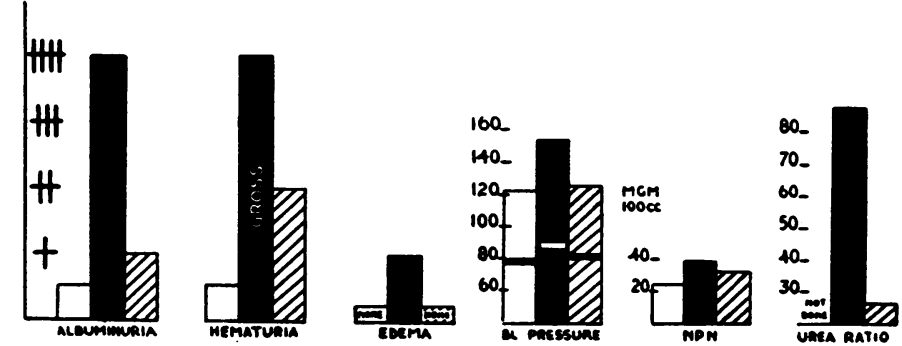

Onset of exacerbation $\mathbf{I}$ 2-12-39

Preceding infection: Pneumococcus ॥ Ethmoidal sinusitis
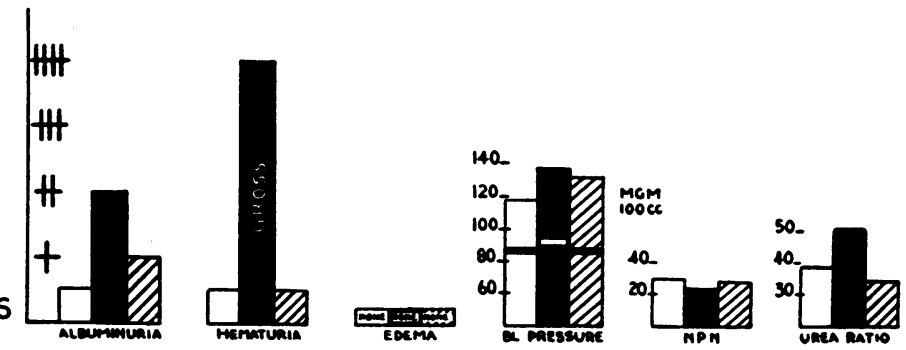

Maxımum finding prior to exacerbation

- Maximum finding during exacerbation Maximum finding after exacerbation

Fig. 2. Case iII (Ro). Observations Before, During, and After Five Exacerbations in Course of Chronic Glomerulonephritis 
found to be 28 per cent and 29 per cent of normal on 2 occasions. Nine months later the urea clearance was 76 per cent of normal.

Exacerbation $V$ developed on February 12, 1939, and was preceded by an ethmoidal sinusitis. Cultures of the pharyngeal exudate showed pneumococcus type XI as the predominating organism. There was no evidence to implicate the hemolytic streptococcus in this infection. The exacerbation in this instance failed to produce any demonstrable effect on renal function.

In summary, this 12-year-old girl with chronic glomerulonephritis of 7 years' duration has been studied through 5 exacerbations in the past 3 years. The 2 exacerbations apparently related to hemolytic streptococcus infection caused a temporary drop in renal function. The exacerbation said to be related to pneumonia is shown to have resulted only in a transient edema. The remaining 2 exacerbations failed to effect detectable drops in renal function. It is of interest that the urea clearance of 28 per cent of normal found during the fourth exacerbation on May 1, 1938, had risen to 76 per cent of normal during the fifth exacerbation on February 15, 1939.

Despite the 5 exacerbations which were observed by us and 4 other exacerbations deduced from the history, this patient shows remarkably good functional reserve at the end of 7 years of extremely active glomerulonephritis, if the frequency of exacerbation is accepted as a criterion of activity. Not only is the urea clearance 76 per cent of normal but the serum nonprotein nitrogen level is $22 \mathrm{mgm}$. per $100 \mathrm{cc}$. and the urea ratio is 45 . The blood pressure is $126 / 82$, there is no edema, the albuminuria is only + and there are so few red blood cells in the urine that the benzidine test is negative.

\section{Case IV (Go)}

This boy died of uremia in March, 1939, at the age of 13. In 1931 at the age of 5 he had had scarlet fever and otitis media. Adequate urinalyses were not performed at that time. Four years later, in March, 1935, he had a severe sore throat followed in 2 weeks by otitis media and edema of the face and ankles. On admission to the Babies Hospital in April, 1935, he was found to have marked anemia, moderate generalized edema, hypertension $(176 / 130)$, slight vascular changes in the ocular fundi, gross hematuria, heavy albuminuria, and numerous granular, hyalin, and red blood cell casts in the urinary sediment. The nonprotein nitrogen level was $55 \mathrm{mgm}$. per $100 \mathrm{cc}$. and the maximum specific gravity of the urine was 1.012. The clinical opinion was that the picture represented an exacerbation in chronic glomerulonephritis, rather than an initial attack of acute glomerulonephritis. It was believed that the latter may have resulted from the scarlet fever in 1931. Despite the presence of chronic pharyngitis, hemolytic streptococci could not be isolated by culture. The antistreptolysin titer, however, was 144 units. This value subsequently dropped to 71 units. This is suggestive evidence that the pharyngitis and otitis media were probably due to the hemolytic streptococcus.

From Figure 3 it is seen that this exacerbation resulted in edema, hypertension and nitrogen retention. There was a reduction in these three abnormalities after the exacerbation.

The subsequent history of this patient shows a gradual

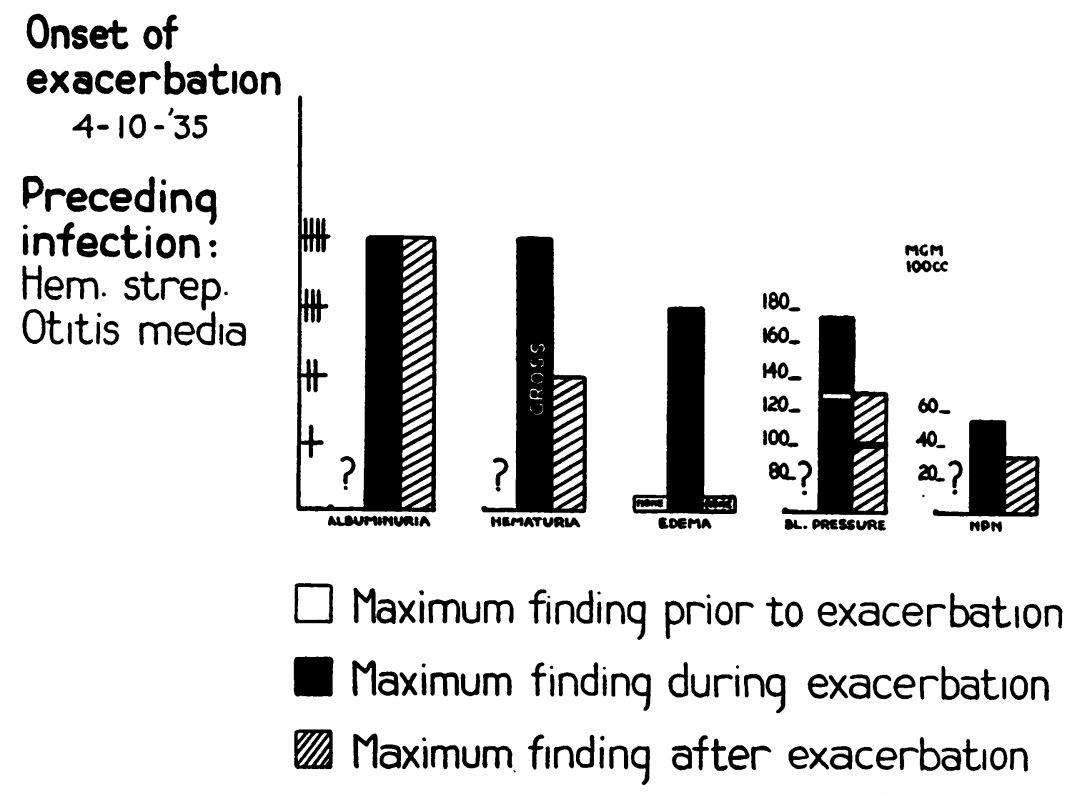

Fig. 3. Case IV (Go). Observations Before, During, and After Exacerbation in Course of Chronic Glomerulonephritis 
reduction in renal competence until death 4 years later in March, 1939.

\section{Case $V(A l)$}

This girl died in December, 1937, of uremia and cardiac failure at the age of 13 . Three years earlier she had developed her first symptoms suggesting nephritis, when hospital examination showed the presence of marked albuminuria, moderate hematuria, moderate generalized edema, cardiac hypertrophy and hypertension $(148 / 100)$.

The serum nonprotein nitrogen was $50 \mathrm{mgm}$. per 100 cc., she was unable to concentrate the urine above 1.015 , and the urea clearance was 36 per cent of normal. Chronically diseased tonsils were removed without incident. On discharge from the hospital the hypertension, edema and urinary findings persisted. Her urea clearance had now dropped to 12 per cent of normal and the urine concentration test was fixed at 1.010 .

The patient first came under our observation in December, 1935, 2 years before her death. At this time, in addition to the manifestations of chronic glomerulonephritis, a marked pansinusitis was found. The exudate from available sinus orifices repeatedly yielded Group A hemolytic streptococci on culture. A bilateral maxillary sinusotomy was performed on December 31, 1935, and again on March 3, 1936, without apparent modification of the nephritic process.

Exacerbation I occurred on February 7, 1936, within 24 hours following the development of an upper respiratory infection and a flare-up of the sinusitis. Within 2 weeks an otitis media developed, but this complication subsided without operation. Group A hemolytic streptococci were isolated from the pharynx during the upper respiratory infection and within 6 weeks the antistreptolysin titer had risen from the base line of 55 units to a peak of 333 units. From Figure 4 it is observed that no striking changes occurred in the edema level, the blood pressure values, or the nonprotein nitrogen figure during this exacerbation.

Exacerbation II occurred on February 5, 1937, and was preceded by a sore throat 4 days earlier. Group A hemolytic streptococci were isolated from the pharynx and the antistreptolysin titer rose from a base line of 71 units to 166 units within 2 weeks. From the chart it may be seen that there was a sharp drop in kidney function associated with this renal flare-up. The serum nonprotein nitrogen level showed a rise from 55 to $95 \mathrm{mgm}$. per $100 \mathrm{cc}$. and the urea ratio reached a high level of 82 . Following the exacerbation the nonprotein nitrogen returned to its approximate pre-exacerbation level and there was striking improvement in the urea ratio.

The subsequent history of this patient was one of progressive decrease in renal reserve, with hypertension and cerebral hemorrhage dominating the picture. There was almost continuous hemolytic streptococcus infection during the 2-year period in which we observed her. Although the presence of this infection may have contributed to the progressive renal damage, it may be stated that, when opportunity was available to follow the patient through a typical bout of hemolytic streptococcus invasion, the harmful effect of renal function was transient. It cannot be denied, however, that the persistence of the hemolytic streptococcus sinusitis may have contributed to progressive renal damage in this patient.

\section{Case VI (Gon)}

This 13-year-old girl developed acute glomerulonephritis probably in April, 1936, following a hemolytic streptococcus cervical lymphadenitis with abscess formation. From her history it was learned that in July, 1936, she had experienced a second attack of cervical lymphadenitis for which incision and drainage was performed. The hemolytic streptococcus was cultivated from the exudate. Slight abnormalities were observed in the urine during this episode but accurate data concerning these changes could not be obtained. The patient spent the next year in Southern Florida and was in apparent excellent health. There were no urinalyses during this period.

She was first seen at Babies Hospital on April 27, 1938, with an exacerbation of nephritis which is described in Figure 5. On April 6, 1938, there was swelling of the neck, vomiting and fever. One week later gross hematuria was observed. One week before admission, on April 20, 1938, an incision and drainage was performed for the relief of the cervical abscess. When first seen by us on April 27, 1938, the patient presented the typical picture of active glomerulonephritis. Cultures of the cervical abscess discharge yielded Group A hemolytic streptococcus. The antistreptolysin titer reached a peak of 715 units.

From the chart it is seen that the first exacerbation is characterized by an increase in albuminuria and hematuria. The figures for blood pressure, serum nonprotein nitrogen, urea ratio and urea clearance show that the function had been impaired during the exacerbation, and that improvement in renal reserve followed the flare-up. Since there is no adequate fore period study with respect to the functional tests, it is impossible to compare the post-exacerbation with the pre-exacerbation levels.

Exacerbation II occurred on December 6, 1938, and appeared to be associated with a recrudescence of the chronic cervical lymphadenitis. This lesion was drained a month later when Group A hemolytic streptococci were again obtained on culture of the purulent discharge. The antistreptolysin titer rose from a base line of 55 units to a peak of 250 units. From the chart it is seen that this exacerbation provoked a slight transient disturbance in kidney function, as shown by the increase in the urea ratio.

In summary, this 13-year-old girl experienced 2 exacerbations of chronic glomerulonephritis which in each instance effected a transient decrease in renal function.

\section{Case VII (Wh)}

On August 4, 1934, at the age of 10, this girl developed edema after a chill which was said to have been 


\section{Onset of \\ exacerbation I}
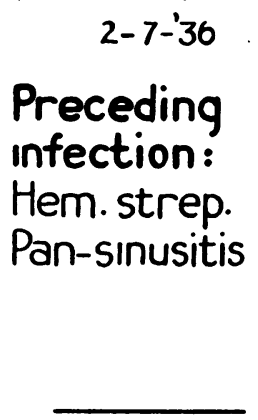
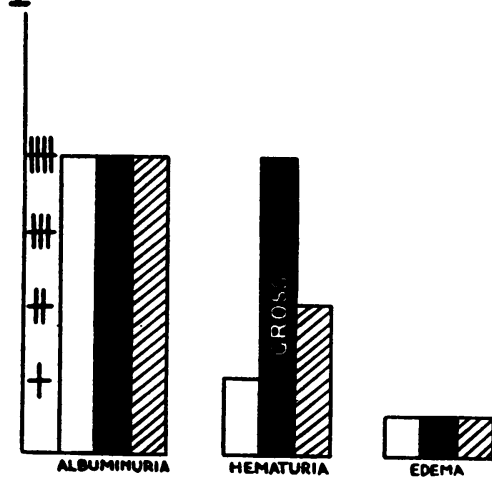

$\underset{\text { Mocr }}{\operatorname{mem}}$

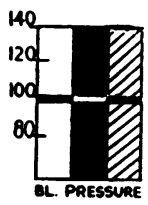

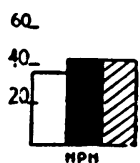

\section{Onset of \\ 2-5 - -37 \\ Preceding infection: Hem. strep. pharyngitis} exacerbation II
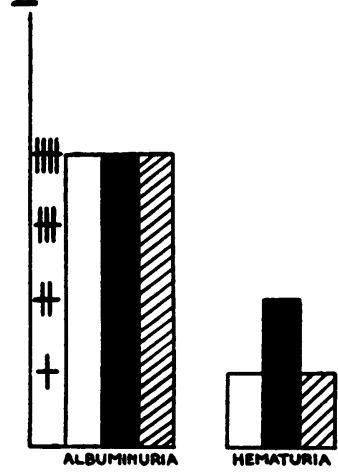

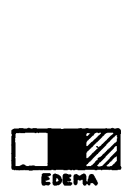

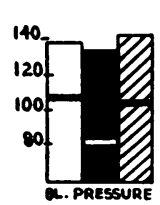
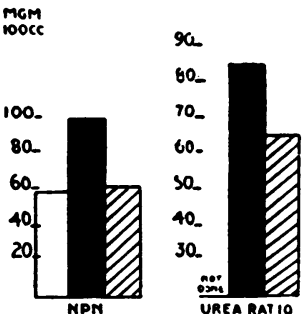

$\square$ Maximum finding prior to exacerbation

\section{Maxımum finding during exacerbation Maxımum finding after exacerbation}

Fig. 4. Case V (Al). Observations Before, During, and After Two Exacerbations in Course of Chronic Glomerulonephritis

induced by swimming. Heavy albuminuria and microscopic hematuria were reported but the blood pressure was not taken. She was first seen by us 5 weeks later on September 17, 1934. At this time she was found to have smoky urine, moderate edema of the face, sacrum and legs, a blood pressure of 190/160, and a serum nonprotein nitrogen value of $44 \mathrm{mgm}$. per $100 \mathrm{cc}$. There was moderate cardiac enlargement and the fundi showed slight edema of the discs and arteriolar spasm. The serum albumin was 2.5 per cent and the serum cholesterol $475 \mathrm{mgm}$. per $100 \mathrm{cc}$. As far as one could tell, this episode represented the initial attack of nephritis.

There was no history of an acute infection prior to this renal episode beyond the description of the chill. However, there was evidence on admission of a chronic pharyngitis and chronic tonsillitis. Group A hemolytic streptococci were cultivated from the throat exudate on admission and from the excised tonsils 3 months later. The antistreptolysin titer on admission was 33 units and remained at this level for the next 9 months.

On December 12, 1934, a tonsillectomy and adenoidectomy were performed. There were no modifications in the urinary findings, the blood pressure values, or degree of edema following this operative procedure. However, the urinary output was diminished for 2 days following operation and the serum nonprotein nitrogen rose from 46 to 50 but 4 days later it had decreased to $31 \mathrm{mgm}$. per $100 \mathrm{cc}$.

On February 7, 1935, she was admitted to the Babies Hospital for study. Although interval observations had 


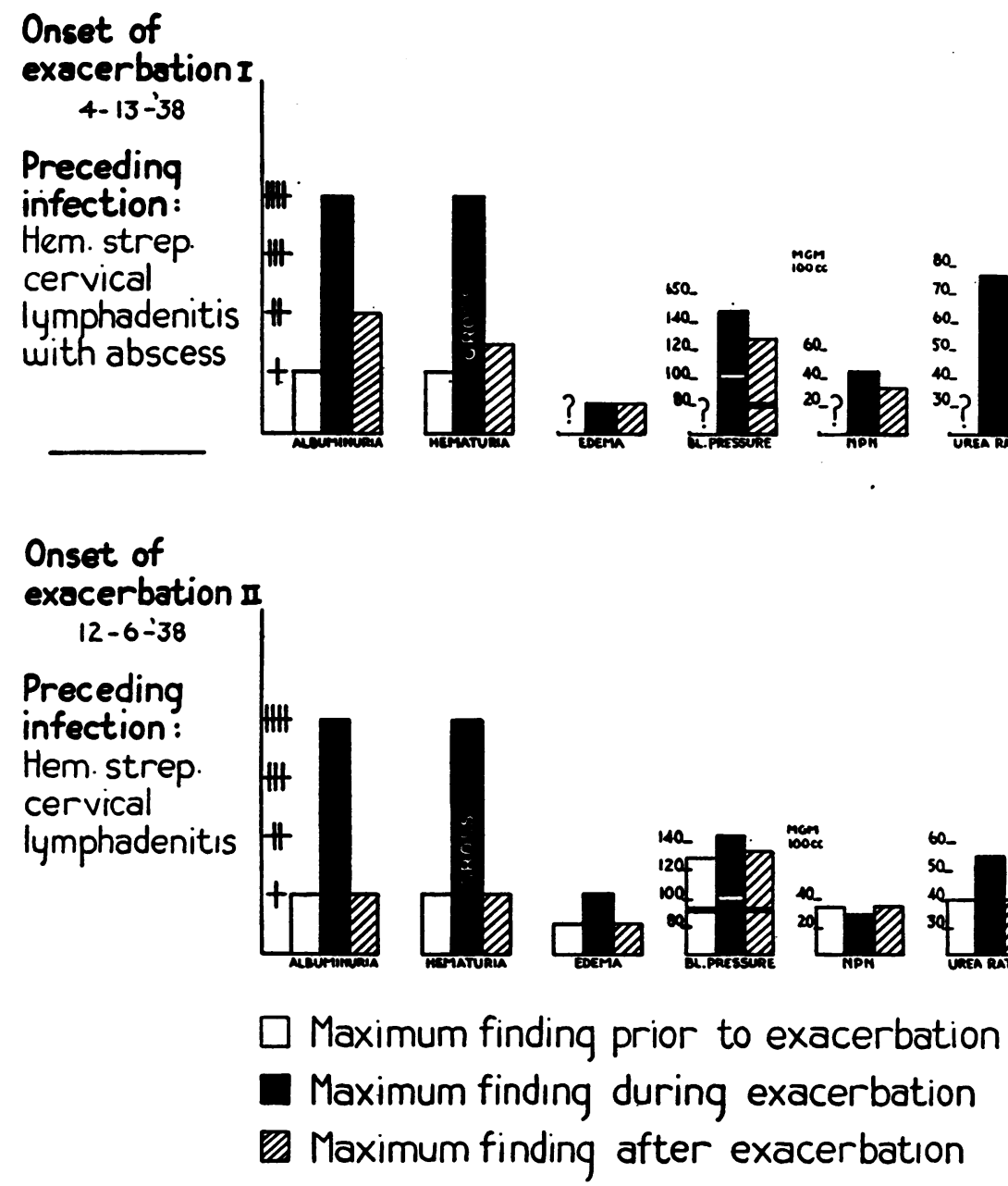

Fig. 5. Case Vi (Gon). Observations Before, During, and After Two Exacerbations in Course of Chronic Glomerulonephritis

not been frequent, there appeared to be clinical improvement. With modified restriction of activity there were no symptoms referable to hypertension or cardiac strain. Facial edema was noted only occasionally and the urinary output was adequate. In the hospital gross hematuria and heavy albuminuria persisted. Slight edema of the face and ankles was present. The blood pressure was $180 / 130$ and the serum nonprotein nitrogen was $36 \mathrm{mgm}$. per $100 \mathrm{cc}$. These findings were similar to those noted on discharge in December, 1934.

On February 21, 1935, this patient contracted scarlet fever. Group A hemolytic streptococci were isolated from the pharynx and the antistreptolysin titer rose from 25 to 333 units. Two and a half months later this value had dropped to 71 units. This antistreptolysin response was of interest in view of the low titer observed in August, 1934, despite the presence at that time of Group A hemolytic streptococci in the pharynx. It is probable that the patient was a carrier of the organism when first seen and that the hemolytic streptococcus had not invaded the tissues sufficiently to produce an antistreptolysin response.

An exacerbation of the nephritis immediately followed the initial signs of scarlet fever. Since the changes in the urine were so marked prior to the onset of scarlet fever, it was difficult to evaluate changes in this respect, but it was observed that the urine became red at the onset of the rash (Figure 6). Although there were no significant changes in the degree of edema or blood pressure, the serum nonprotein nitrogen level rose from 36 to $86 \mathrm{mgm}$. per $100 \mathrm{cc}$. during the course of the scarlet fever. One month later this value had dropped to 34 mgm. per $100 \mathrm{cc}$. Although other tests for renal function were not done, it would appear that a transient decrease in renal reserve was induced by the attack of scarlet fever.

This patient was followed for 3 more years until her death on January 21, 1938. In this period she had 3 infections, one of which was shown to be Group A hemolytic streptococcus otitis media. During this epi- 


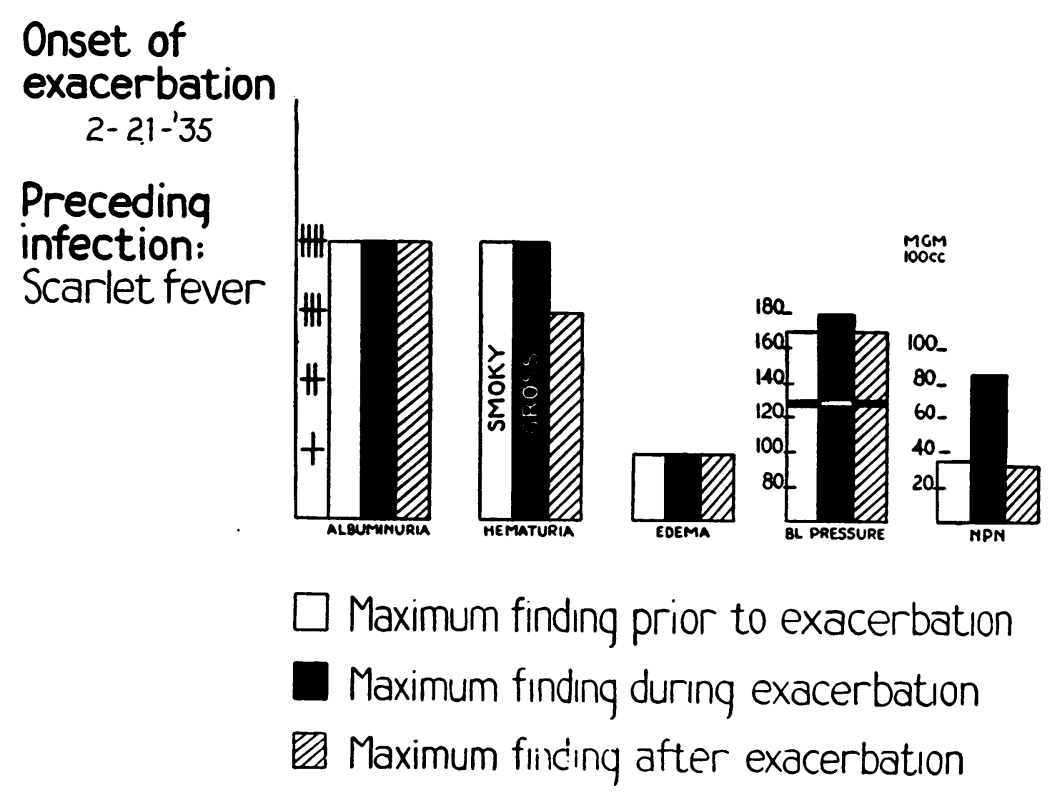

Fig. 6. Case ViI (Wh). Observations Before, During, and After Exacerbation in Course of Chronic Glomerulonephritis

sode the patient was followed outside the hospital and renal function tests were not performed. Death was apparently due to cardiac failure. Autopsy was not permitted.

\section{Case VIII (Le)}

This 14-year-old boy had a history of hematuria, malaise, and headache in July, 1938. There was no history of preceding infection, but when he was observed for the above symptoms he was found to have otitis media, and 1 week later he developed a sore throat. The albuminuria and hematuria diminished but persisted and he was admitted to the Presbyterian Hospital in September, 1938. Physical examination was negative except for a blood pressure of 140/90. The hemoglobin was 76 per cent, albuminuria varied from ++ to +++ , and there were 1-30 red blood cells per high power field. The serum protein was 7.3 grams per $100 \mathrm{cc}$., the nonprotein nitrogen $33 \mathrm{mgm}$. per $100 \mathrm{cc}$., and the phenolsulphonphthalein excretion 55 per cent. There were no hemolytic streptococci on throat culture and the antistreptolysin titer was 71 units. The diagnosis was active glomerulonephritis.

In December, 1938, 3 days after exposure to "chilling," he developed gross hematuria. There was a history of a cough following the "chilling." Group A hemolytic streptococci were not found in the throat, but the antistreptolysin titer rose from a base line of 71 to 100 units and later fell to 50 units. Group $F$ hemolytic streptococci were isolated from the throat on 3 occasions. As shown in the table below, there was no evidence for significant changes in renal function during this exacerbation.

\begin{tabular}{|c|c|c|c|}
\hline & $\begin{array}{c}\text { Before } \\
\text { exacerbation }\end{array}$ & $\begin{array}{c}\text { During } \\
\text { exacerbation }\end{array}$ & $\begin{array}{c}\text { After } \\
\text { exacerbation }\end{array}$ \\
\hline $\begin{array}{l}\text { Hematuria } \ldots \ldots \ldots \\
\text { Edema ............ } \\
\text { Blood pressure..... } \\
\text { Nonprotein nitrogen } \\
\text { Urea ratio.......... }\end{array}$ & $\begin{array}{c}++ \\
0 \\
120 / 90 \\
30\end{array}$ & $\begin{array}{c}\text { gross } \\
0 \\
145 / 80 \\
35 \\
50\end{array}$ & $\begin{array}{c}++ \\
0 \\
135 / 82 \\
28 \\
40\end{array}$ \\
\hline
\end{tabular}

In February, 1939, he developed gross hematuria one day after a head cold. No hemolytic streptococci were cultivated from the pharynx and the antistreptolysin titer did not rise. As shown in the table, the exacerbation caused no significant change in renal function.

\begin{tabular}{|c|c|c|c|}
\hline & $\begin{array}{c}\text { Before } \\
\text { exacerbation }\end{array}$ & $\begin{array}{c}\text { During } \\
\text { exacerbation }\end{array}$ & $\begin{array}{c}\text { After } \\
\text { exacerbation }\end{array}$ \\
\hline 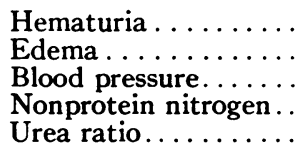 & $\begin{array}{c}++ \\
0 \\
135 / 85 \\
30 \\
42\end{array}$ & $\begin{array}{c}\text { gross } \\
0 \\
148 / 98 \\
37 \\
46\end{array}$ & $\begin{array}{c}+ \\
0 \\
114 / 80 \\
30 \\
50\end{array}$ \\
\hline
\end{tabular}

In this patient 2 exacerbations occurring in a 3-month period produced no significant changes in renal function.

\section{Case IX $(K e)$}

This 15-year-old boy was known to have had rheumatic fever and chorea at the age of 10 . At that time his physician observed the development of an apical systolic murmur. In January, 1936, at the age of 12 , he developed painless edema of his ankles and his blood pressure was elevated. However, a single urinalysis 
was reported to show no abnormality at that time. The edema of the ankles was of short duration and he was in apparent good health until May, 1937, when he had a severe sort throat with fever of $103^{\circ}$. This was quickly followed by the development of erythema nodosum of both lower legs. Two weeks after his sore throat his urine became bloody and edema of the eyelids and ankles was noted.

He was first seen by us on July 9, 1937, when he was believed to have subacute glomerulonephritis. Frequent urinalyses showed the presence of ++++ albumin with many red blood cells and a few granular casts in the sediment. The serum nonprotein nitrogen was $41 \mathrm{mgm}$. per $100 \mathrm{cc}$. and the blood pressure of $135 / 90$ at bed rest was considered slightly elevated for a boy of 13 . The serum cholesterol was $312 \mathrm{mgm}$. per $100 \mathrm{cc}$. The only evidence suggesting active rheumatism was furnished by the electrocardiogram. The $\mathrm{P}-\mathrm{R}$ interval rose from 0.16 to 0.20 and there were form changes consistent with the diagnosis of rheumatic myocarditis. These form changes disappeared within 3 weeks but the $P-R$ interval remained 0.20 for the next 2 years.

This patient was observed closely in the following 2 years. In November, 1938, he had a Group A hemolytic streptococcus throat infection without demonstrable exacerbation of nephritis or rheumatic fever. Of interest is the fact that the albuminuria which had been ++++ for 16 months, dropped to ++ with the onset of this Group A hemolytic streptococcus pharyngitis and persisted at this level for the next $3 \frac{1}{2}$ months until a fresh Group A hemolytic streptococcus infection appeared to increase the albuminuria to its previous ++++ level.

On March 25, 1939, the patient developed a sore throat following coryza. Group A hemolytic streptococci were isolated from the throat 40 times in the next $21 / 2$ months. The antistreptolysin titer rose from a base line of 144 to a peak of 333 units. This was considered adequate evidence for hemolytic streptococcus infection. Within the next 2 months evidence for an exacerbation of the rheumatism rested on the development of a painful right wrist and an increase in the $P-R$ interval from 0.20 to 0.24. In addition, $\mathrm{ST}_{1}$ and $\mathrm{ST}_{2}$ were slightly elevated. The albuminuria which had been ++ for 4 months rose to ++++ . In this same 4 -month period the red blood cells in the urine had been reported as being absent or rare except for 2 of 9 examinations when the maximum value was one red blood cell per high power field.

From the Addis counts it was shown that the preinfection output of $3,000,000$ white blood cells had risen to $75,000,000$ after the pharyngitis. The excretion of red blood cells rose from $4,000,000$ to $50,000,000$ after the pharyngitis. The urea ratio, which on 3 occasions between January 17, 1939, and March 25, 1939, had been between 29 and 31 , rose to a maximum of 55 and subsequently dropped to 40 . However, the serum nonprotein nitrogen level showed no change. There was no edema, but the blood pressure reached a maximum of $180 / 120$ with this episode. In the subsequent 3 months the blood pressure had decreased, but persisted at a higher level than was observed in the pre-exacerbation phase. There were no demonstrable eye-ground changes. The phenolsulphonphthalein excretion was always over 75 per cent.

It would appear that an exacerbation of rheumatic fever and glomerulonephritis occurred in this boy following a Group A hemolytic streptococcus infection. The evidence for a decrease in function associated with the nephritis is meager, being based only on the rise in the urea ratio.

\section{Case $X(E d)$}

This 17-year-old Negro was known to have had glomerulonephritis for at least 4 years previous to our first examination 8 months before his death. Early in life he was found to have congenital syphilis for which he received vigorous treatment. When seen by us his blood Kline test was strongly positive.

Early in October, 1938, he developed coryza outside the hospital. This was quickly followed by the development of generalized edema with an increase in the degree of hematuria as compared with the previous values observed 2 months earlier. Although Group A hemolytic streptococcus was not recovered from his pharynx, his antistreptolysin level rose from 83 to 333 units.

The effect of this hemolytic streptococcus infection on the renal status of this patient is shown in Figure 7. The degree of albuminuria changed from ++ to ++++ and remained so until his death 4 months later. The degree of hematuria rose from + to +++ with the exacerbation but then dropped to a minimum. The average Addis count for red blood cells in the prolonged postexacerbation period was $1,000,000$ for the nocturnal 12 hour period. The changes in edema, blood pressure, nonprotein nitrogen retention, and phenolsulphonphthalein excretion noted in Figure 7 indicate that, whereas the period of hematuria was associated with the development of marked edema, the other values were not strikingly abnormal in this same period. The patient was considered to have lapsed into the nephrotic state of chronic glomerulonephritis. The serum protein value was 4.0 grams per $100 \mathrm{cc}$. with the albumin 1.7 grams per 100 cc. The serum cholesterol was $305 \mathrm{mgm}$. per $100 \mathrm{cc}$. Although no further hemolytic streptococcus infections could be demonstrated, there was a progressive drop in renal function beginning about 3 months after the onset of the exacerbation. The water retention became almost maximal, the blood pressure mounted to $230 / 130$ and the serum nonprotein nitrogen level rose to $171 \mathrm{mgm}$. per $100 \mathrm{cc}$. The phenolsulphonphthalein excretion, which had been 40 per cent, dropped to zero per cent within the next 2 months.

The patient died on April 9, 1939, of acute cardiac failure. The autopsy showed the renal lesions typical of chronic glomerulonephritis. Bismuth inclusions were found in the renal tubules. There was no histological evidence of acute glomerulonephritis.

From our study of this patient we were led to conclude that a hemolytic streptococcus infection had apparently induced an exacerbation of nephritis which at first assumed the pattern usually described as the ne- 


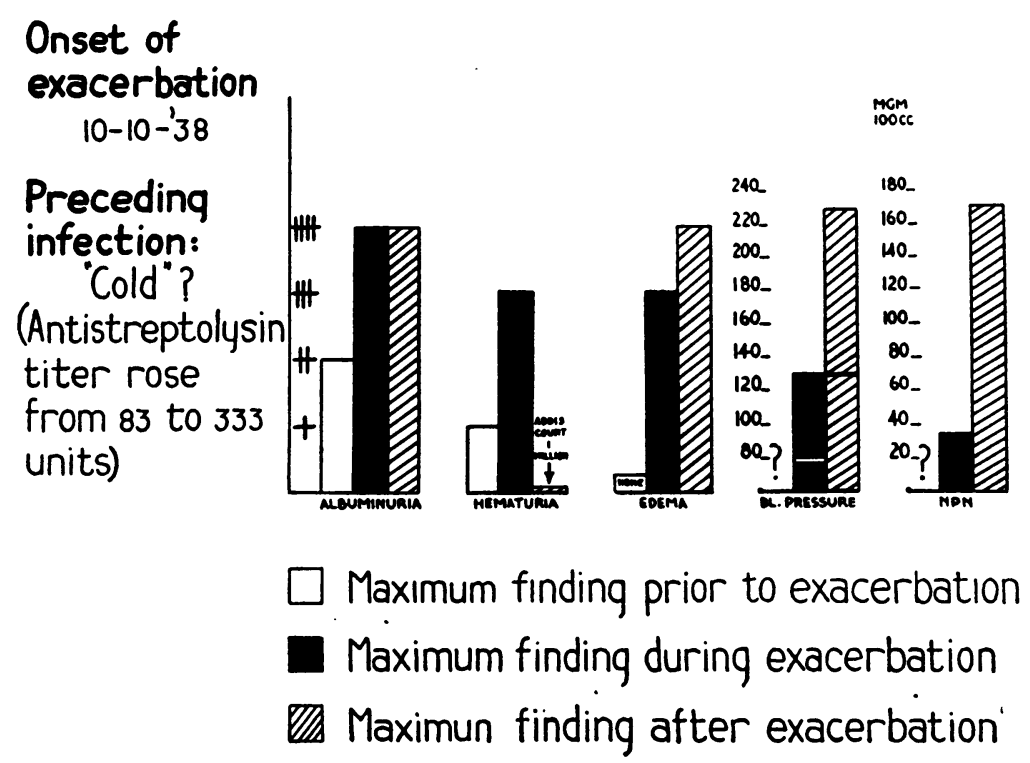

Fig. 7. Case X (Ed). Observations Before, During, and After Exacerbation in Course of Chronic Glomerulonephritis

phrotic stage of chronic glomerulonephritis. It was not until 3 months after the onset of the exacerbation that a progressive decrease in renal function appeared independent of the disturbance in the salt-water equilibrium. It is possible that in this patient the hemolytic streptococcus infection initiated an exacerbation which resulted in a permanent drop in the renal function, but it cannot be denied that the progressive renal failure might have occurred in the absence of the infection.

\section{Case $X I(P a)$}

This 17-year-old girl apparently developed acute glomerulonephritis in Puerto Rico at the age of 14 . She gave a history of recurrent ulcers of both legs as a child but had never developed lymphedema of the extremities. It was of interest that the last episode of chronic ulceration of the legs terminated about 1 month prior to the onset of acute glomerulonephritis. The patient did not recall an upper respiratory infection prior to the onset of her initial attack of hematuria. During the next 2 years there were two attacks of gross hematuria, one in Puerto Rico and one in New York City. No data are at hand concerning prodromal infection with these episodes.

Two weeks prior to her admission to Presbyterian Hospital in May, 1939, she was said to have passed "red" urine. This persisted for 4 days. A few days after the onset of hematuria she was aware of a cold and 5 days later she had a sore throat with dysphagia.

When she was admitted to the hospital 1 week after the sore throat her pharynx was still red and her temperature was $101^{\circ}$. One out of 18 throat cultures showed a Group A hemolytic streptococcus. Her first antistreptolysin titer was found to be $\mathbf{5 0 0}$ units. This value rose to 1250 units and 4 months later had dropped to
250 units. The evidence would thus suggest that the exacerbation occurred concomitant with a hemolytic streptococcus infection.

From Figure 8 it is seen that the hematuria characteristic of the exacerbation is a transient finding. It is of interest that in this patient there is evidence that the exacerbation initiated a diuresis since the patient showed no edema during the acute phase of the renal flare-up in contrast to the data prior to and after the exacerbation. This finding is unrelated to salt restriction since water retention occurred in the post-exacerbation period despite the maintenance of a diet similar to that provided during the exacerbation. From the data on the chart concerning the phenolsulphonphthalein excretion and the serum nonprotein nitrogen values, it is apparent that a transient drop in renal function occurred during the renal flare-up.

\section{Case XII $(D u)$}

This 18-year-old girl had been observed by us for 55 months prior to her death from uremia on November 29,1938 . At the age of 9 she had had scarlet fever with cervical lymphadenitis. In her tenth year she was reported to have had 3 severe sore throats, 2 of which were complicated by a peritonsillar abscess. A persistent albuminuria was detected about this time. At the age of 13 edema first appeared and the diagnosis of chronic glomerulonephritis was established.

She was first seen by us on April 19, 1934. In the following 55 months 2 frank exacerbations of the nephritis occurred. The first bout appeared one day after a mild sore throat on December 9, 1934. A hemolytic streptococcus was recovered from the pharynx but failed to grow on subculture when attempts at grouping were made. An adequate series of antistreptolysin determinations showed no rise above the previous base line of 25 


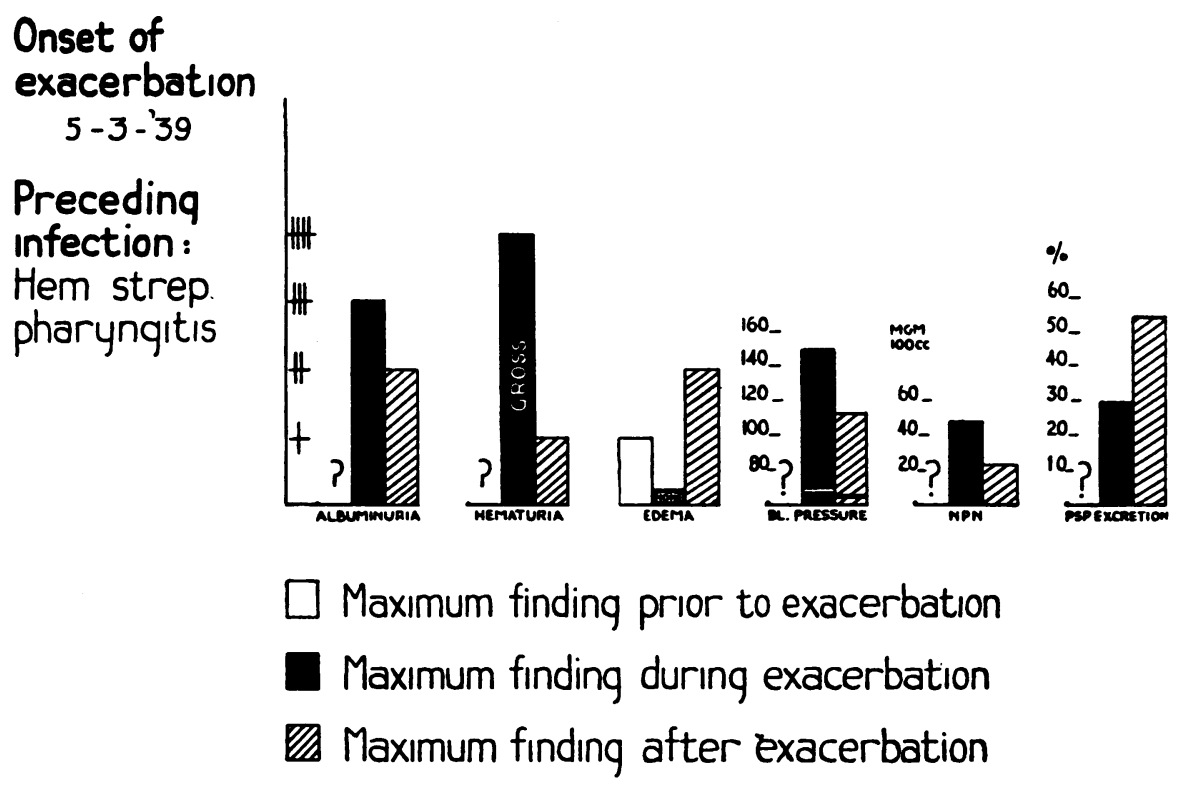

Fig. 8. Case XI (Pa). Observations Before, During, and After Exacerbation in Course of Chronic Glomerulonephritis

units. It was concluded, therefore, that there was insufficient evidence at hand to incriminate the hemolytic streptococcus as the cause of the exacerbation. The latter was characterized by gross hematuria. Urinalyses prior to the exacerbation had always shown many red blood cells in the sediment with some reports describing the sediment as saturated with red blood cells. The effect of this exacerbation on renal function was as follows: The minimal degree of edema remained unchanged. The pre-exacerbation blood pressure of $130 / 88$ rose to $155 / 100$ and the blood urea value rose from 30 to $47 \mathrm{mgm}$. per $100 \mathrm{cc}$. When the gross hematuria terminated, only 20 red blood cells per high power field could be found in each of 50 urine sediment examinations over a 2-month period. It was of interest, therefore, that the degree of hematuria immediately following the exacerbation was less than that observed in the pre-exacerbation period. Although the blood pressure continued at the exacerbation level, blood urea determinations showed that a normal value was reached after the exacerbation.

The second exacerbation followed a prolonged hemolytic streptococcus infection beginning on April 13, 1935. A sore throat associated with a shaking chill and high fever was followed by an acute cervical lymphadenitis and otitis media. These infections subsided without surgical intervention. Hemolytic streptococci were isolated from the pharynx 1 month after the onset of the sore throat. It was impossible to obtain earlier cultures since the patient was outside the hospital in a convalescent home. This infection was followed by a rise in the antistreptolysin titer from the base line of 33 units to a peak of 250 units.
Within 2 days following the onset of the sore throat, gross hematuria supervened. The bloody urine persisted for 5 days and then disappeared to return 4 weeks later following a recrudescence of the pharyngitis and cervical lymphadenitis. There was a temporary increase in the degree of edema and in the serum nonprotein nitrogen level during the exacerbation. The pre-exacerbation serum nonprotein nitrogen of 30 rose to $40 \mathrm{mgm}$. per 100 cc. during the renal flare-up, but a subsequent blood urea determination in the post-exacerbation period was within normal limits. Evidence was not obtained to prove a drop in renal function. It was of interest that the pre-exacerbation degree of hematuria of 80 to 100 red blood cells per high power field was decreased to 10 to 15 red blood cells per high power field following the second bout of gross hematuria. This lower value persisted for 2 months.

In the 31/2-year period following the last exacerbation the patient was seen on 21 occasions. Seven colds and 2 sore throats occurred during this time. Group A hemolytic streptococci could not be recovered from the pharynx during these visits and the antistreptolysin titer was always between 25 and 50 units. The nephritis progressed, with microscopic hematuria and increasing hypertension the dominant features. Acute cardiac insufficiency manifested by dyspnea, even at bed rest, and nocturnal dyspnea characterized the final months of her illness. There was no edema. She died in uremia. Terminally, there were convulsive seizures and pulmonary edema. The autopsy findings were those of chronic glomerulonephritis.

\section{Case XIII (Mo)}

This 33-year-old man was rejected for life insurance in 1933 because of obesity. Albuminuria and slight cylin- 
duria without hematuria were demonstrated in 1936. In June, 1937, he developed pneumonia. Information concerning the etiology of this infection is not at hand. One week after the onset of the pneumonia gross hematuria appeared associated with renal colic. The blood pressure was $115 / 80$ to $130 / 80$ at that time. His physician ascribed this abnormality to renal calculus but subsequent $\mathrm{x}$-rays failed to disclose the presence of a stone in the urinary tract. The pneumonia terminated and he was out of bed 3 weeks after onset. Except for epistaxis and frontal headache appearing about once a week, he was well for the next 6 months. Early in December, 1937 , he developed an upper respiratory infection associated with cough and dyspnea. His headache and epistaxis became more severe and 1 week after the onset of the upper respiratory infection gross hematuria and edema developed.

He was first seen by us on December 29, 1937, 2 weeks after the onset of hematuria and the edema. The pharynx was injected but repeated throat cultures failed to reveal the presence of hemolytic streptococci. However, the antistreptolysin titer was 333 units. This level subsequently fell to 71 units. The latter data indicated a recent hemolytic streptococcus infection. During the first week in the hospital he was critically ill, being practically anuric for the first 24 hours. Figure 9 illustrates the available data concerning the urinary findings and certain functional tests in the periods before, during, and after the exacerbation.

It is seen that the gross hematuria during the exacerbation was reduced to a ++ level within 2 months. This degree of hematuria persisted unchanged for the next 19 months. The nonprotein nitrogen value of 175 mgm. per $100 \mathrm{cc}$. during the exacerbation returned to a normal value of $30 \mathrm{mgm}$. per $100 \mathrm{cc}$. in 2 months and has persisted at this level. Similarly, the phenolsulphonphthalein excretion value of 3 per cent during the exacerbation, was 45 per cent in the fifth month, and 60 per cent in the eleventh month after the exacerbation. The edema disappeared following the exacerbation and the hypertension was markedly reduced. Almost 2 years after the exacerbation the only evidence for hypertension is noted in the diastolic phase where the values run between 87 and 105 .

During the sixteenth month following the exacerbation, the patient experienced a severe sore throat. The antistreptolysin titer rose from the base line of 71 units to 200 units, though the few throat cultures which were available failed to reveal the presence of hemolytic streptococci. Gross hematuria did not supervene and the degree of albuminuria was unchanged. There were no significant changes in the renal function tests, all of which remained normal.

In summary, this 33-year-old man had apparently had chronic glomerulonephritis for at least 2 years before a pneumonia induced a gross hematuria. He was not observed by us through this episode. Six months later, however, a proved hemolytic streptococcus infection produced a major exacerbation of his nephritis. A profound decrease in renal function resulted, but additional study showed that this drop was temporary rather than permanent. It was of interest that 16 months following this exacerbation a hemolytic streptococcus pharyngitis failed to produce gross evidence of an exacerbation and did not impair renal function, which appeared normal by the usual tests.

\section{Onset of exacerbation} $12-15-37$
Preceding
infection:
Hem. strep.
Upper resp.
infection
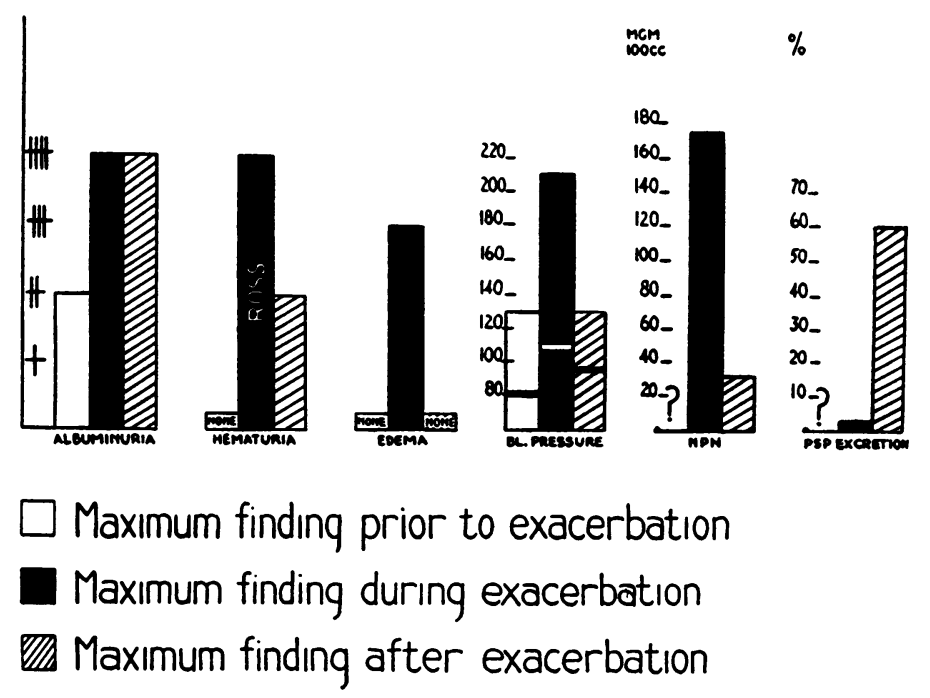

Fig. 9. Case XiII (Mo). Observations Before, During, and After Exacerbation in Course of Chronic Glomerulonephritis 


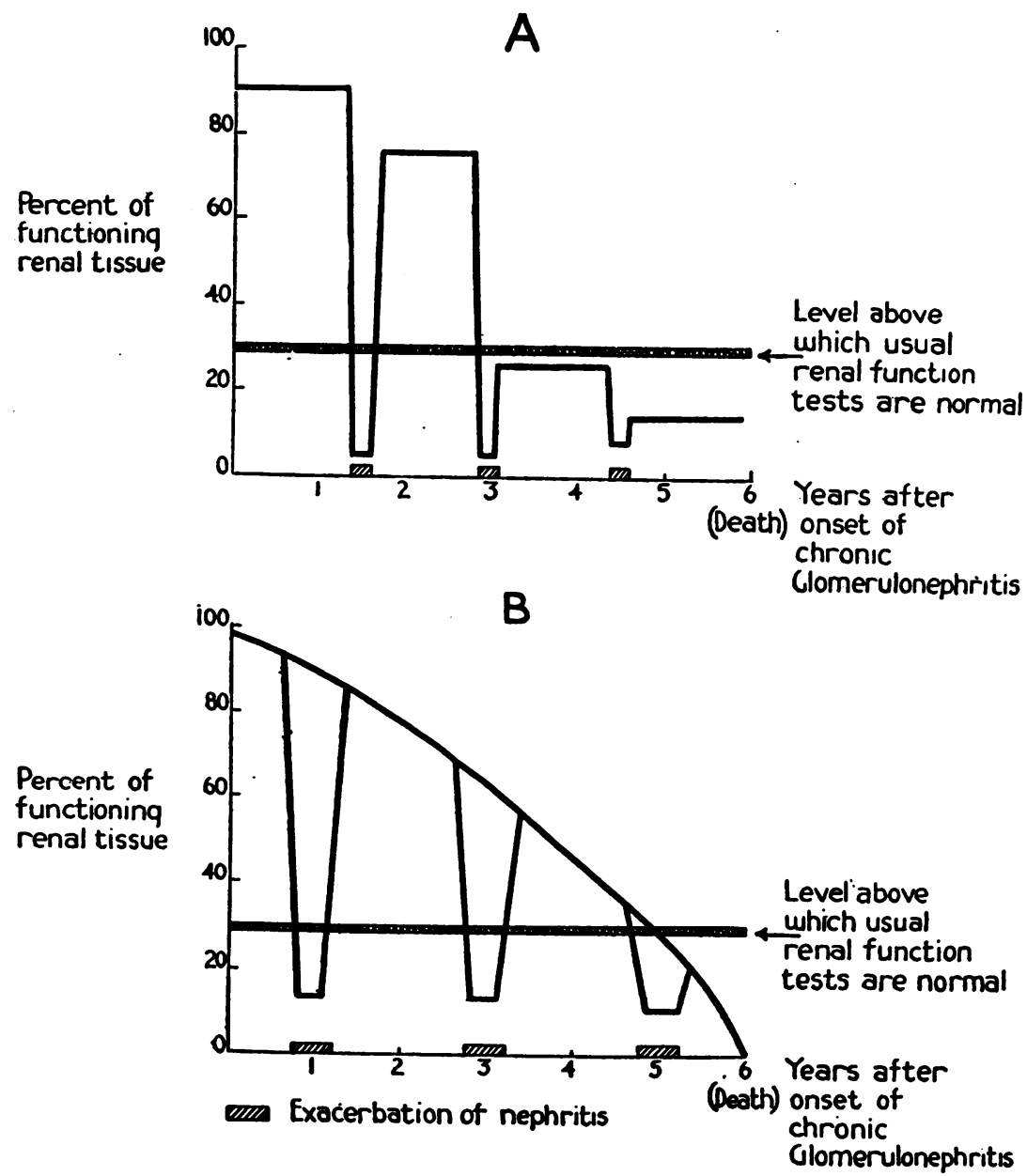

Fig. 10. Schematic Description ( $A$ and $B$ ) Showing Two Possible Effects of Exacerbation on Mass of Functioning Renal Tissue in Hypothetical Patient with Chronic Glomerulonephritis

\section{BIBLIOGRAPHY}

1. Loeb, R. F., Clinical aspects of nephritis. Bull. New York Acad. Med., 1938, 14, 65.

2. Winkenwerder, W. L., McLeod, N., and Baker, M., Infection and hemorrhagic nephritis. Arch. Int. Med., 1935, 56, 297.

3. Seegal, D., and Lyttle, J. D., Unpublished studies.

4. Seegal, D., and Heidelberger, M., Streptococcus scarlatinae; volume of 48 hour broth culture required to yield sufficient nucleoprotein to produce skin and constitutional reactions in susceptible individuals. J. A. M. A., 1933, 100, 186.

5. Mosenthal, H. O., and Bruger, M., The urea ratio as a measure of renal function. Arch. Int. Med., 1935, 55, 411.

6. Longcope, W. T., O'Brien, D. P., Mcguire, J., Hansen, O. C., and Denney, E. R., Relationship of acute infections to glomerular nephritis. J. Clin. Invest., 1927, 5, 7.

7. Longcope, W. T., The pathogenesis of glomerular nephritis. Bull. Johns Hopkins Hosp., 1929, 45, 335.

8. Longcope, W. T., Studies of the variations in the antistreptolysin titer of the blood serum from patients with hemorrhagic nephritis. I. Control observations on healthy individuals and patients suffering from diseases other than streptococcal infections. J. Clin. Invest., 1936, 15, 269.

9. Addis, T., Haemorrhagic Bright's disease. I. Natural history. Bull. Johns Hopkins Hosp., 1931, 49, 203.

10. Osman, A. A., Studies in Bright's disease. XII. The late-results of acute nephritis in soldiers and civilians. Guy's Hosp. Rep., 1936, 86, 93.

11. Leiter, L., Renal function. Internat. Clinics, 1935, 3, 24. 